\title{
Awareness and Attitude Regarding Teenage Pregnancy among Adolescent Girls of Chandannath Municipality, Jumla
}

Shrestha Sharmila ${ }^{1 *}$, Monika Lama ${ }^{2}$, Sujata Ojha ${ }^{2}$, Savina Thapa ${ }^{2}$

${ }^{1}$ Associate Professor, Karnali Academy of Health Science, School of Nursing and Midwifery, Jumla, Nepal

${ }^{2}$ Lecture, Karnali Academy of Health Science, School of Nursing and Midwifery, Jumla, Nepal

*Corresponding author: Shrestha Sharmila, Associate Professor, Karnali Academy of Health Science, School of Nursing and Midwifery, Jumla, Nepal

Received date: March 28, 2021; Accepted date: April 22, 2021; published date: May 17, 2021

Citation: Shrestha Sharmi, Monika Lama, Sujata Ojha, Savina Thapa.(2021) Awareness and Attitude Regarding Teenage Pregnancy among Adolescent Girls of Chandannath Municipality, Jumla. J. Women Health Care and Issues 4 (4); DOI: 10.31579/2642-9756/049

Copyright: (C) 2021 Shrestha Sharmila, This is an open access article distributed under the Creative Commons Attribution License, which permits unrestricted use, distribution, and reproduction in any medium, provided the original work is properly cited.

\section{Abstract}

Background: Teenage pregnancy is a major threat to adolescent health globally which remains a challenging issue requiring urgent resolution over the world.

Objectives: To find out to awareness and attitude regarding teenage pregnancy among adolescent girls.

Materials and Methods: A descriptive cross- sectional design was carried out among 334 adolescent girls of school students of Chandannath Municipality, Jumla.

Results: More than half of adolescent girls (68\%) had inadequate, $26 \%$ had moderate and least $6 \%$ had adequate awareness regarding teenage pregnancy. However, majority $(58.1 \%)$ of adolescent girls had favorable attitude, that they believed teenage pregnancy as wrong while only (34.4\%) of them had neutral attitude and least (7.5\%) of them had unfavorable attitude which support teenage pregnancy. There was no relation between awareness and attitude regarding teenage pregnancy and types of family, level of education of father and mother.

Conclusion: In this study, half of respondents had inadequate awareness regarding teenage pregnancy even though majority of them had favorable attitude regarding teenage pregnancy. There was no significant difference between demographic variables with awareness and attitude regarding teenage pregnancy. The study had highlighted the need for awareness program regarding teenage pregnancy in school as well as in community.

Keywords: teenage pregnancy; awareness; attitude; adolescent girls

\section{Introduction}

According to WHO, adolescence is identifying as the period in human growth and development that occurs after childhood and before adulthood, from ages 10 to19 and it is divided into three phases early (1013 years), mid (14-16 years) and late (17-19 years) [1]. Adolescents are not fully capable of understanding the relationship between behavior and consequences making them particularly vulnerable to sexual exploitation and high-risk behaviors putting themselves at high risk for unintended pregnancies [2]. World health organization defines Teenage Pregnancy as "any pregnancy from a girl who is 10-19 years of age," the age being defined as her age at the time the baby is born [2].

Teenage pregnancy remains a challenge requiring urgent resolution over the world [3] teenage pregnancy is a major threat to adolescent health globally. The complications linked to pregnancy and childbirth is the second cause of death for 15 to 19 years' old girls worldwide [4]. (Around 1 in 6 persons in the world is an adolescent that is 1.2 billion [3]. About 16 million women of 15 to19 years old give birth each year worldwide, and the vast majority are in low- and middle-income countries. World
Health Statistics 2014 put the global adolescent birth rate at 49 per 1000 girls aged 15-19 years [2]

Furthermore, World Health Organization [2], estimates that 6 million adolescents are giving birth each year in Member States of the South-East Asia Region. Much of teenage pregnancy occurs within marriage, especially in Bangladesh, India and Nepal, where early marriage of girls is still common. The median age that girls marry is 17.8 years in Nepal which is one of the causes of teenage pregnancy [5].

Likewise, India has increasing incidence of teenage pregnancy which is an important factor in the population rise. As per census 2011, total number of adolescent populations in India is $20.9 \%$ of the total population. This rate is highest in the state of Jharkhand (28\%) followed by West Bengal $(25 \%)$ and Bihar $(25 \%)$ which all are states of eastern India [6].

Nepal is one of the countries of predominance of traditional societies, where marriage and childbearing for many women still occur at an earlier age than the legal age of marriage, especially among certain ethnic groups. Adolescents make up about $24.19 \%$ of the population in Nepal. 
Around $17 \%$ of girls from 15-19 years are already mothers or pregnant with their first child [5]. This percentage is increasing rapidly from one percent among those aged 15 to $39 \%$ in those aged 19 . In the hill region $16 \%$ of pregnancies were in adolescents compared to terai (18\%) [5].

In addition, teenage pregnancy is both a cause and consequence of right violations. Pregnancy challenges a girl's possibilities for exercising the rights to education, health and autonomy, as guaranteed in Convention on the Rights of the Child. [3] Some of the studies concluded that pregnant teenagers had significantly higher knowledge compared to non-pregnant teenagers and most of adolescents held negative attitude towards teenage pregnancy $[7,8]$.

Teenage pregnancy is considered a high-risk pregnancy as death due to pregnancy related causes is double among women aged 15 to 19 years compared to women in their twenties. Also lack of education and unawareness of contraceptive methods make the situation worse [9].

Furthermore, teenage pregnancy is associated with negative obstetric, fetal as well as social consequences like anemia, unsafe abortion, postpartum hemorrhage, and postpartum depression, obstetric fistula as terrible consequences among $65 \%$ of women, preterm birth, low birth weight, asphyxia and early school dropout which has long-term effects on them, their families and communities. Studies have shown that delaying adolescent births could significantly lower population growth rates, potentially generating broad economic and social benefits, in addition to improving the health of adolescents. [2]

The Programmer of Action of the International Conference on Population and Development recognized that providing adolescents with information is the first step towards reducing adolescent pregnancies and unsafe abortions [10]. A descriptive study revealed that students get only $29 \%$ of reproductive health education from schools as well as less awareness of family life education are contributory factors of teenage pregnancy [11]. Similarly, another study conducted among adolescent girls of government junior colleges in Tirupathi, India showed only 34\% had adequate knowledge towards teenage pregnancy [12]. While another study found that the adolescents had poor attitude towards teenage pregnancy [13]. A study concluded that teenage mothers would have delayed the pregnancy if they had known its consequences beforehand [7]. Above overall studies showed that adolescent girls had lack of education of reproductive health as contributing factors of teenage pregnancy where they had less knowledge and poor attitude towards teenage pregnancy. The main objective of this study was to find out to awareness and attitude regarding teenage pregnancy among adolescent girls.

\section{The aim of the study was:}

- $\quad$ To assess the level of awareness regarding teenage pregnancy among adolescent girls.

- To explore the attitude regarding teenage pregnancy among adolescent girls.

- To find out the association between selected demographic variables and level of awareness regarding teenage pregnancy among adolescent girls.

- To find out the association between selected demographic variables and attitude regarding teenage pregnancy among adolescent girls.

\section{Materials and Methods}

Research Design: Descriptive cross-sectional design based on quantitative approach was adopted to identify the awareness and attitude regarding teenage pregnancy among adolescent girls of higher secondary school of Chandannath Municipality Jumla.
Research Population: Adolescent's girls of grade nine and ten students of higher secondary schools of Chandannath Municipality Jumla. There is total nine higher secondary schools in Chandannath Municipality. Among the nine higher secondary schools, five schools were selected by simple random method for data collection. Total 334 students are included in this study.

\section{Sampling Technique}

Enumerative sampling method was used in five selected higher secondary schools in Chandannath Municipality

Inclusion Criteria: All adolescent girls of grade nine and ten students, aged 13-19 years and consented to participate was included in the study.

Instrumentation: Self-administered structured questionnaire was developed on the basis of extensive review of literature [12, 14]. And consultations with experts. The research instrument consists of three parts, Part I questions assessed the demographic characteristics of adolescent girls, Part II questions assessed the awareness regarding teenage pregnancy and Part III Statements assessed the attitude regarding teenage pregnancy among adolescent girls.

Firstly, English version questionnaire was developed then converted to Nepali version. In this study Nepali version questionnaire will used to collect information. The study questionnaire was divided into three parts.

Part I: Description of demographical variables

Part II: Questions related to awareness regarding teenage pregnancy Part III: Statements related to attitude regarding teenage pregnancy.

\section{Scoring Criteria for Awareness}

Awareness related questionnaires consisted of 12 questions on Part-II which was mixed of multiple-choice questions and multiple responses for which each right answer of multiple-choice questions and each multiple response was scored 1. Thus, the total score of awareness was 48. Similarly, the analysis of awareness level (14) was done as:

Inadequate level of awareness - Score less than 24 ( $<50$ percent)

Moderate level of awareness - Score $24-36$ (50 - 75 percent)

Adequate level of awareness - Score more than 36 (> 75 percent)

\section{Scoring Criteria for Attitude}

Attitude related statements consisted of nine statements on Part-III which was mixed of seven positive and two negative statements. The total score of attitudes was 45. A response was collected under categories: strongly agree [5], agree [4], undecided [3], disagree [4], strongly disagree [1] for positively stated statements [3-9] while reverse coding was done for negatively stated statements

[1-2] Thus analysis of attitude level [13] was done as Total score is 45:

Unfavorable attitude - Score less than 23 ( $<50$ percent)

Neutral attitude - Score $21-34$ (50 - 75 percent)

Favorable attitude - Score more than 34 (> 75 percent)

\section{Validity}

The content validity of the instrument was established through consultation with peers and external subject matter experts. The questionnaire was translated into Nepali and back translated into English with the linguistic experts (English and Nepali).

\section{Reliability}

Pre-testing of the instrument was done among $10 \%$ of similar population. The validity and reliability of the questionnaire was assessed and the 
questionnaire was found highly reliable and valid. Crohnbach's alpha was found 0.76 .

\section{Ethical Consideration:}

An ethical approval was obtained from the Institutional Review Board (IRB) of KAHS and study area. An informed consent was taken from

\begin{tabular}{|c|c|c|}
\hline Categories & Frequency & Percentage \\
\hline \multicolumn{3}{|l|}{ Age (years) } \\
\hline 13 & 12 & 3.6 \\
\hline 14 & 79 & 23.7 \\
\hline 15 & 130 & 38.9 \\
\hline 16 & 92 & 27.5 \\
\hline 17 & 21 & 6.3 \\
\hline \multicolumn{3}{|l|}{ Grade } \\
\hline Nine & 186 & 55.7 \\
\hline Ten & 148 & 44.3 \\
\hline \multicolumn{3}{|l|}{ Caste } \\
\hline Bramhan & 120 & 35.9 \\
\hline Chhetri & 132 & 39.5 \\
\hline Dalit & 39 & 11.7 \\
\hline Janajati & 33 & 9.9 \\
\hline Others & 10 & 3 \\
\hline \multicolumn{3}{|l|}{ Types of family } \\
\hline Nuclear & 170 & 50.9 \\
\hline single & 144 & 43.1 \\
\hline Extended & 19 & 5.7 \\
\hline \multicolumn{3}{|l|}{ Marital status } \\
\hline Unmarried & 326 & 97.6 \\
\hline Separate & 8 & 2.4 \\
\hline \multicolumn{3}{|l|}{ Father's education } \\
\hline Illiterate & 76 & 22.8 \\
\hline Primary & 54 & 16.2 \\
\hline Secondary & 115 & 34.4 \\
\hline High-secondary & 68 & 20.4 \\
\hline University & 21 & 6.3 \\
\hline \multicolumn{3}{|l|}{ Father's occupation } \\
\hline Business & 103 & 30.8 \\
\hline Farmer & 109 & 32.6 \\
\hline Office & 122 & 36.5 \\
\hline \multicolumn{3}{|l|}{ Mother's education } \\
\hline Illiterate & 182 & 54.5 \\
\hline Primary & 85 & 25.5 \\
\hline Secondary & 49 & 14.7 \\
\hline high-secondary & 15 & 4.5 \\
\hline University & 3 & 0.9 \\
\hline \multicolumn{3}{|l|}{ Mother's occupation } \\
\hline Business & 37 & 11.1 \\
\hline Farmer & 219 & 65.6 \\
\hline Housewife & 48 & 14.4 \\
\hline Office & 30 & 9 \\
\hline
\end{tabular}

Demographic characteristics $(n=334)$

Table 1 shows that the mean age for the participants was 15.09 years (standard deviation [SD] 0.95, range 13-17).

participants by main researcher. Confidentiality of the participants was maintained. The information was not shared with anyone other than those involved in the study. No participants were forced to participate or stay in the study.

\section{Results:

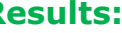


Participant's level of awareness regarding teenage pregnancy $(n=334)$

Table 2 shows that out of total adolescent girls, more than half of the respondents 227 (68\%) had inadequate awareness while 87 of adolescent girls $(26 \%)$ had moderate awareness and only 20 respondents $(6 \%)$ had adequate awareness regarding teenage pregnancy. The mean score of awareness was $21.57 \pm 7.39$.

\begin{tabular}{|c|c|c|}
\hline Level of attitude & Frequency & Percentage \\
\hline unfavorable & 25 & 7.5 \\
\hline Neutral & 115 & 34.4 \\
\hline Favorable & 194 & 58.1 \\
\hline Total & 334 & 100.0 \\
\hline Mean score \pm SD: $33.90 \pm 6.98$ & & \\
\hline
\end{tabular}

Adolescent girls' level of attitude regarding teenage pregnancy $(n=334)$

Table 3 shows that among total adolescent girls only 25 (7.5\%) had unfavorable attitude while $34.4 \%$ had neutral attitude and more than half of them (58.1\%) had favorable attitude regarding teenage pregnancy. Furthermore, overall level of attitude had mean score (33.90 \pm 6.98$)$.

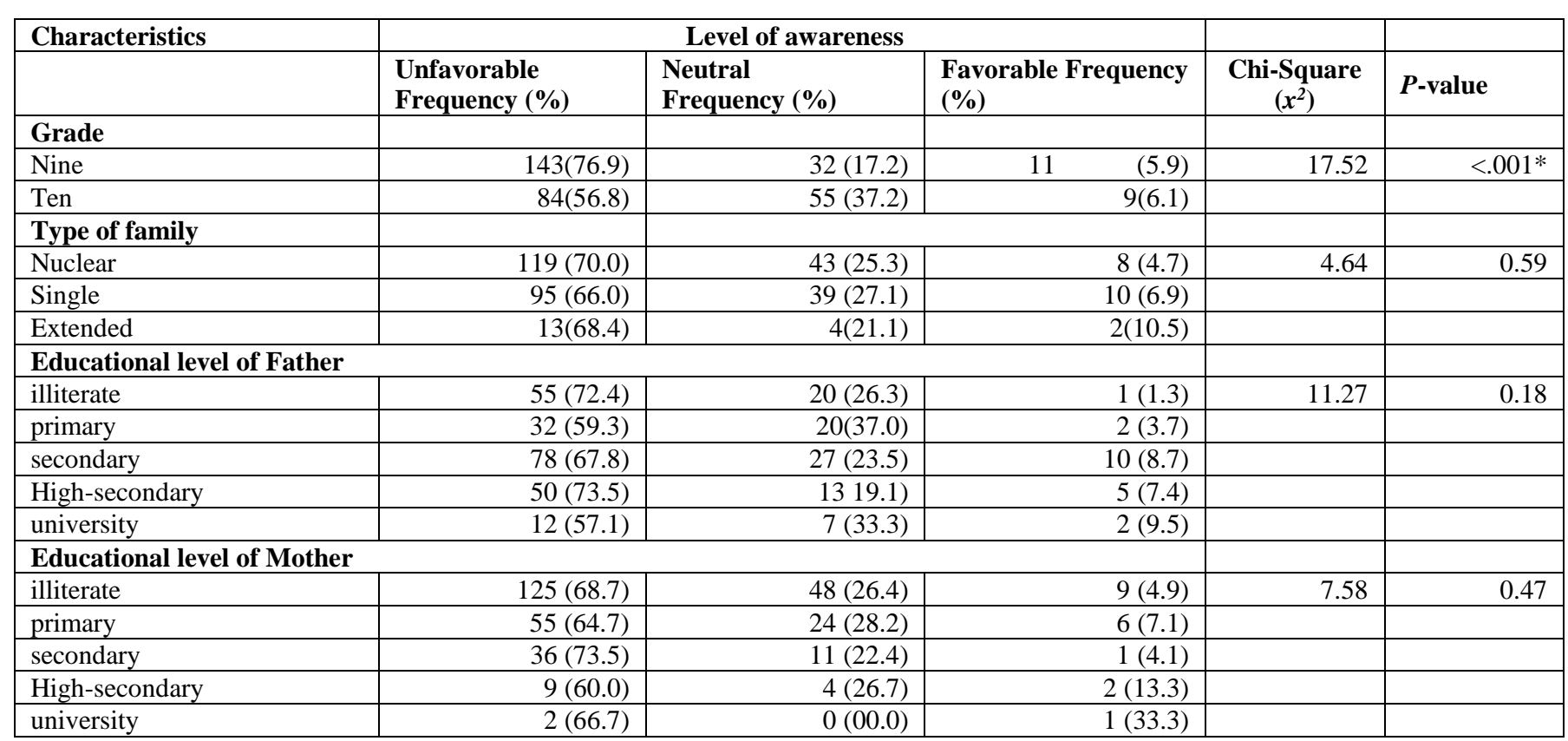

Note. *: p value significant at $(P<.05)$

Association of demographic characteristics of adolescent girls and level of awareness regarding teenage pregnancy $(n=334)$

In table 4, there is no statistically significant association between awareness and types of family, education level of respondents' fathers and mothers $(x 2=4.64, p=0.4),(x 2=11.27, p=0.18),(x 2=7.58, p=0.47)$. However, there was significant association between participants grade and level of awareness $(x 2=17.52, p<0.001)$.

\begin{tabular}{|c|c|c|c|c|c|}
\hline \multirow[t]{2}{*}{ Characteristics } & \multicolumn{3}{|c|}{ Level of attitude } & \multirow[b]{2}{*}{ Chi-Square $\left(x^{2}\right)$} & \multirow[b]{2}{*}{$P$-value } \\
\hline & $\begin{array}{l}\text { Unfavorable } \\
\text { Frequency }(\%)\end{array}$ & $\begin{array}{l}\text { Neutral } \\
\text { Frequency }(\%)\end{array}$ & $\begin{array}{l}\text { Favorable } \\
\text { Frequency }(\%)\end{array}$ & & \\
\hline \multicolumn{6}{|l|}{ Grade } \\
\hline Nine & $17(9.1)$ & $75(40.3)$ & $(50.5)$ & 9.83 & $<.007 *$ \\
\hline Ten & $8(5.4)$ & $40(27)$ & $100(67.6)$ & & \\
\hline \multicolumn{6}{|l|}{ Type of family } \\
\hline Nuclear & $15(8.8)$ & $66(38.8)$ & $89(52.4)$ & 9.16 & 0.16 \\
\hline Single & $10(6.9)$ & $46(31.9)$ & $88(61.1)$ & & \\
\hline Extended & $0(0.0)$ & $3(15.8)$ & $16(84.2)$ & & \\
\hline \multicolumn{6}{|c|}{$\begin{array}{l}\text { Educational level of } \\
\text { Father }\end{array}$} \\
\hline illiterate & $8(10.5)$ & $27(35.5)$ & $41(53.9)$ & 11.64 & 0.17 \\
\hline primary & $7(13.0)$ & $23(42.6)$ & $24(44.4)$ & & \\
\hline secondary & $7(6.1)$ & $40(34.8)$ & $68(59.1)$ & & \\
\hline High-secondary & $3(4.4)$ & $19(27.9)$ & $46(67.6)$ & & \\
\hline university & $0(0.0)$ & $6(28.6)$ & $15(71.4)$ & & \\
\hline
\end{tabular}




\begin{tabular}{|c|c|c|c|c|c|}
\hline \multicolumn{6}{|c|}{ Educational level of Mother } \\
\hline illiterate & $19(10.4)$ & $63(34.6)$ & $100(54.9)$ & 11.44 & 0.18 \\
\hline primary & $5(5.9)$ & $33(38.8)$ & $47(55.3)$ & & \\
\hline secondary & $0(0.0)$ & $16(32.7)$ & $33(67.3)$ & & \\
\hline High-secondary & $1(6.7)$ & $3(20.0)$ & $11(73.3)$ & & \\
\hline university & $0(0.0)$ & $0(00.0)$ & $3(100)$ & & \\
\hline
\end{tabular}

Note. *: $p$ value significant at $(P<.05)$

Association of demographic characteristics of adolescent girls and level of attitude regarding teenage pregnancy $(N=334)$

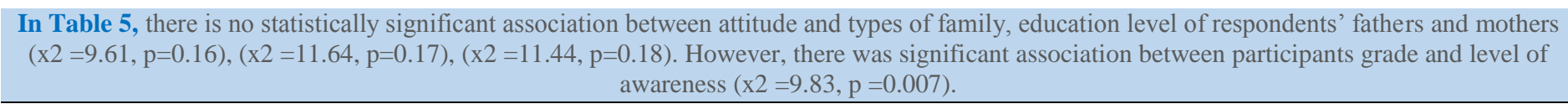

\section{Discussion}

In this study, more than half of the respondents $227(68 \%)$ had inadequate awareness while 87 of adolescent girls $(26 \%)$ had moderate awareness and only 20 respondents $(6 \%)$ had adequate awareness regarding teenage pregnancy. The mean score of awareness was $21.57 \pm 7.39$. (Table 2). The reason for moderate and inadequate level of awareness among adolescent girls might be due to education level, cultural acceptance for early marriage, living in rural areas and less strictness by guardians in trying to monitor activities were contributing factor of teenage pregnancy [15]. In our study more than half of the participants $(55.9 \%)$ were beginning of grade nine and chapter about adolescence sexual and reproductive health is included in the text book of secondary level (grade 9). A study conducted by Siddharth \& Kirubamani [16] concluded that lack of formal education $(91 \%)$ was the most common cause regarding awareness on adolescent pregnancy.

A phenomenological study on lived experiences of early pregnancy among teenagers was conducted in Philippines that include ten teenage mothers, which showed that curiosity, lack of sexual knowledge that had big impact in teenagers who engaged in early sexuality, financial and family problems and uncontrolled emotions cause pregnancy among teenagers. The informants revealed that they did not get any responsible sexual information at school. This study concluded that sex and sexuality education should not just be a concept but should be developed further as a complete discipline [17].

In present study, the findings on attitude regarding teenage pregnancy showed that among total adolescent girls more than half $(58.1 \%)$ of them had favorable attitude, that they believed teenage pregnancy as wrong while only $(34.4 \%)$ of them had neutral attitude and least $(7.5 \%)$ of them had unfavorable attitude which support teenage pregnancy which might be due to their negative feelings towards teenage pregnancy (Table 3). This was similar to study by Osaikhuwuomwan and Osemwenkha [8] that showed majority of respondents held a negative attitude about adolescent pregnancy with over $85 \%$ regarding it as wrong and considered it to be associated with medical, socio-economic and educational problems. Similarly, study conducted Eastern Poland, [18] supports the findings of this study where participants' attitude towards pregnancy was that they think teenage pregnancy as a problem and have a negative effect on parent and child. Likewise, this study is supported by another study that revealed adolescents had neutral attitude towards teenage pregnancy [12]

\section{Conclusion}

Based on the findings, the study concluded that more than half of girls had inadequate awareness regarding teenage pregnancy even though majority of them had favorable attitude regarding teenage pregnancy. There was no significant difference between demographic variables with awareness and attitude regarding teenage pregnancy. The study had highlighted the need for awareness in order to prevent teenage pregnancy to secure the right to health and education of adolescents.
Several limitations should be mentioned for this study. First, the study was conducted in the selected school of Chandanath Municipality with a sample of only nine and ten grades female students due to time and manpower constraints, so it requires replication in other schools and community with male and female students. For the study only one Municipality of Jumla was chosen for data collection so need to collect from different Municipality from different area.

The findings of the study can serve as a source of reference for further studies. The study findings may be helpful to bring consciousness among curriculum makers to bring necessary changes in students' curriculum which emphasized on provision of adolescent reproductive health lesson in school through health workers for better understanding. In addition, government should give more consideration on provision of adolescent friendly health services in health facilities to adolescent girls through trained nurse to create awareness regarding teenage pregnancy. The result might provide guidelines for planning awareness program regarding teenage pregnancy in school as well as community.

An educational intervention study on teenage pregnancy among adolescents can be conducted. Additional have a qualitative study on lived experiences of early pregnancy among teenagers. Same as, a comparative study can be conducted on awareness and attitude regarding teenage pregnancy among adolescent girls of rural and urban area.

\section{References:}

1. United Nations Children Fund. (2015). Young child survival and development. Retrived from

2. World Health Organization (WHO), Global health estimates 2015: deaths by cause, age, sex, by country and by region, 2000-2015. Geneva: WHO; 2016.

3. United Nations Population Fund. Girlhood, not motherhood: preventing adolescent pregnancy. New York: UNFPA; 2015.

4. Gurung, R., Målqvist, M., Hong, Z., Poudel, P.G., Sunny, A.K., Sharma, S., Mishra, S., Nurova, N. and Kc, A., 2020. The burden of adolescent motherhood and health consequences in Nepal. BMC pregnancy and childbirth, 20, pp.1-7.

5. Ministry of Health and Population (MoHP), Nepal New ERA and ICF International Inc. Nepal Demographic and Health Survey 2016. Kathmandu: Ministry of Health and Population; 2017.

6. Nandi J, Burman S, Das D, DP SS. Socio-cultural factors influencing teenage pregnancy in rural West Bengal. India. 2014;4(8):670-673.

7. Dulitha F, Nalika G, Upul S, Chrishantha WM, De Alwis SR, Hemantha S. Risk factors for teenage pregnancies in Sri Lanka: perspective of a community-based study. Health Science Journal. 2013 Jul 1;7(3):269.

8. Osaikhuwuomwan JA, Osemwenkha AP. Adolescents' perspective regarding adolescent pregnancy, sexuality and contraception. Asian pacific journal of reproduction. $2013 \mathrm{Mar}$ 


\section{1;2(1):58-62.}

9. Kayastha S, Pradhan A. Obstetric outcome of teenage pregnancy. Nepal Journal of Obstetrics and Gynaecology. 2012;7(2):29-32.

10. Kirby DB, Baumler E, Coyle KK. The Impact of 'Safer Choices' on Condom Use and Contraceptive Use Among Sexually Experienced Students at Baseline. Unpublished manuscript. 2011.

11. Kafle PP, Pakuryal K, Regmi R, Luintel S. Health problems and social consequences in teenage pregnancy in rural Kathmandu Valley. Nepal Med Coll J. 2010 Mar 1;12(1):42

12. Manjula, P., Sreelatha, M. and Sudharani, P., 2016. A Study to Assess the Knowledge of Adolescent Girls towards Teenage Pregnancy at Selected Government Junior Colleges, Tirupathi. Community and Public Health Nursing, 1(2), pp.8994.

13. Opara PI, Eke GK, Tabansi PN. Perception of sexuality education amongst secondary school students in Port Harcourt, Nigeria. West African journal of medicine. 2012;31(2):109113.

14. Rani, M., Sheoran, P., Kumar, Y. and Singh, N., 2016.
Evaluating the effectiveness of pubertal preparedness program in terms of knowledge and attitude regarding pubertal changes among pre-adolescent girls. Journal of family \& reproductive health, 10(3), p.122.

15. Chalise $S$, Bajracharya S. Contributing factors of teenage pregnancy among pregnant teenagers at selected hospitals of Dhaulagiri Zone. Journal of Chitwan Medical College. 2016;6(3):8-13.

16. Siddharth AR, Kirubamani NH. Awareness about Consequence of Teenage Pregnancy. Journal of Evolution of Medical and Dental Sciences. 2019 Aug 26;8(34):2672-2677.

17. Pogoy AM, Verzosa R, Coming NS, Agustino RG. Lived experiences of early pregnancy among teenagers: A phenomenological study. European Scientific Journal. 2014 Jan $1 ; 10(2)$.

18. Bałanda-Bałdyga, A., Pilewska-Kozak, A.B., Łepecka-Klusek, C., Stadnicka, G. and Dobrowolska, B., 2020. Attitudes of Teenage Mothers towards Pregnancy and Childbirth. International journal of environmental research and public health, 17(4), p.1411.

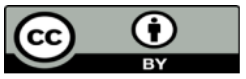

This work is licensed under Creative Commons Attribution 4.0 License

\section{To Submit Your Article Click Here: Submit Manuscript}

DOI: $10.31579 / 2642-9756 / 049$
Ready to submit your research? Choose Auctores and benefit from:

* fast, convenient online submission

* rigorous peer review by experienced research in your field

* rapid publication on acceptance

* authors retain copyrights

* unique DOI for all articles

* immediate, unrestricted online access

At Auctores, research is always in progress.

Learn more https://www.auctoresonline.org/journals/women-healthcare-and-issues- 